\title{
Intelligent Community Design Based on Computer Networks
}

\author{
Wu CHEN ${ }^{1, a}$ \\ ${ }^{1}$ The engineering \& technical college of chengdu university of technology, leshan, 614000 ,china; \\ awchen_leshan@126.com
}

Keywords:network technology, intelligent community, automatic control, internet of things

\begin{abstract}
With the development of network technologies, computer networks provide better and better service for the human. The intelligent Community System is the integrated product of the modern building technology, the computer network technology and the automatic control technology, which facilitates the people to the greatest extent and highly improves safety of human living environment. In this paper, the principles and methods to build the intelligent community network system are analyzed, so as to provide guidance for construction of the system.
\end{abstract}

\section{Introduction}

In recent years, China has step into the information society, people's working and living are increasingly related to communication and information. While the information society changes our lifestyle and work habits, a challenge is being given to the traditional residence. The people have increasingly high requirements for living conditions and hope to get safe, comfortable and convenient houses, therefore the intelligent communities boom through China and become development mainstream of the construction industry in the 21st century.

The intelligent community is spread and extended from the intelligent building, in which the efficient, comfortable, harmonious, convenient and safe dwelling environment requiring reasonable investment is provided by comprehensive consideration of four basics elements (structure, system, service, management and their internal relations) in the groups of buildings. In addition, the computer network becomes gradually essential in the people's lives.

\section{Purpose of building the intelligent community network system}

The intelligent community system is the result (see Fig.1) from integration of the modern building technology, the computer network technology and the automatic control technology, which will provide more perfect service and management for the community, smart management methods for residents' lives, improve property management level of the community, so as to achieve rapid and efficient property service and provide more convenient, safer and more comfortable dwelling environment.

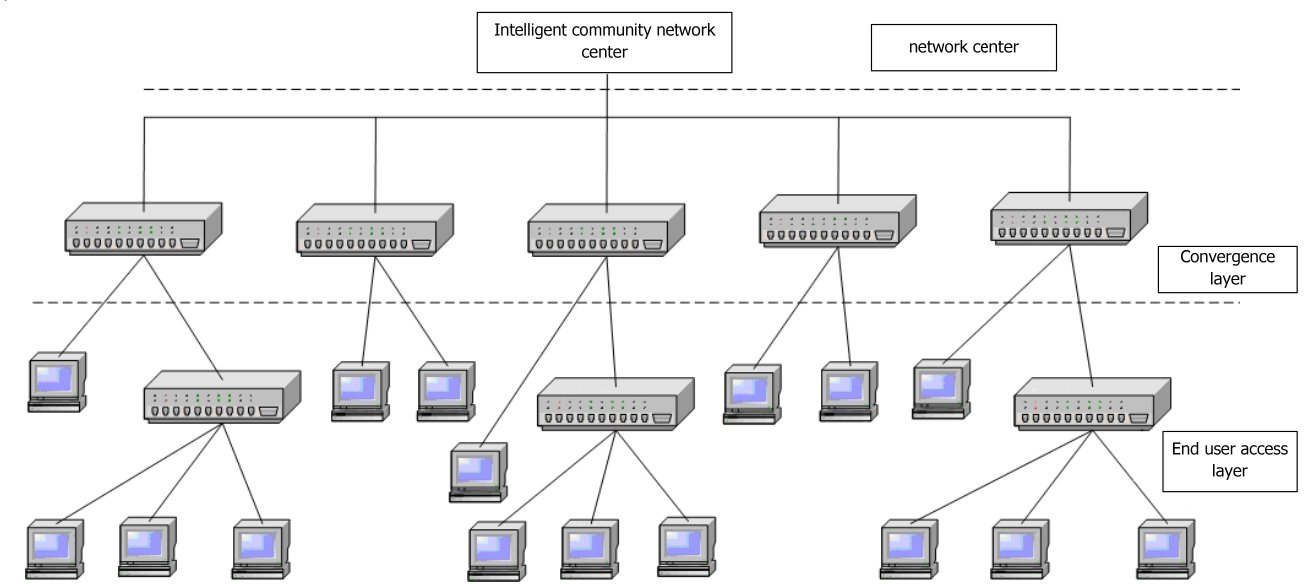

Fig.1.Broadband Access Diagram in Intelligent Community 
1) Properties service and management include the followings: integrated information service of properties, such as charge and settlement etc.; remote meter reading and management, such as reading of water, electric, gas and heating installation meters and relevant charge; entering \& leaving and parking management of vehicles; monitoring and management of common devices, such as storage and transportation of the rubbish, watering gardens and pollution discharge etc.; bulletin board management, broadcast or music playing management and so on.

2) Security work includes residential access control, community circumference defense, electronic patrol, television circumference, intercom and access control, anti-theft and disaster prevention alarms, SOS etc.

3) Multi-information services includes the integrated information network such as e-commerce, distance education, telemedicine, Internet, etc.; public TV, VOD; remote control of switches etc.

4) Intelligent SOHO includes home telecommuting, regulation of the indoor environment and intelligent control of household appliances and so on.

\section{Principles in building intelligent community network system}

It can be seen from the purpose to build the intelligent community that community intelligentization is intended to enhance comprehensively quality of residents' dwelling environment.

For this reason, construction of the intelligent community network should comply with the following principles:

1) Foresight principle: The construction of intelligent buildings is designed to adapt to the level of social development and residents' living requirements, so building the intelligent community should be forward-looking. For example, in the 1980s, the household appliances in Chinese families were scarce, so supporting facilities and the place for the equipment was not required to be taken into account during housing construction. However, in recent years, television sets, refrigerators, washing machines and other household appliances have been used in every family, therefore, relevant supporting facilities must be fully considered in current residential construction. For example, telephone, computer wiring and the related information receiving platform etc. should be included. In addition, the community is one of big-ticket items with a very long life, so some advanced intelligent system and smart devices should be chosen so as to prevent the intelligent community from being eliminated due to low performance caused by outdated technologies.

2) Maturity principle: while foresight of the technical equipment is considered, attention should also be paid to reliability and maturity of the selected technologies, so as to ensure stable operation of the smart equipment and maximize the investment benefits.

Compatibility principle: the intelligent equipment and system depending on the computer network technology should be highly compatible both in system devices and in operating software for the sake of frequent upgrade of the technologies, so as to prevent the system from being incompatible due to different hardware types.

4) Principle of upgrade: Along with the continuous development and progress of the society, scale, technological level and functions of the intelligent community system will be increasingly improved as well, and residents have changing demands for intelligentization of the residential community, therefore, future feasibility and adaptability of the system should be considered together in the intelligent community system, so as to meet updating and developing requirements of intelligent community services.

\section{Construction of the intelligent community network system}




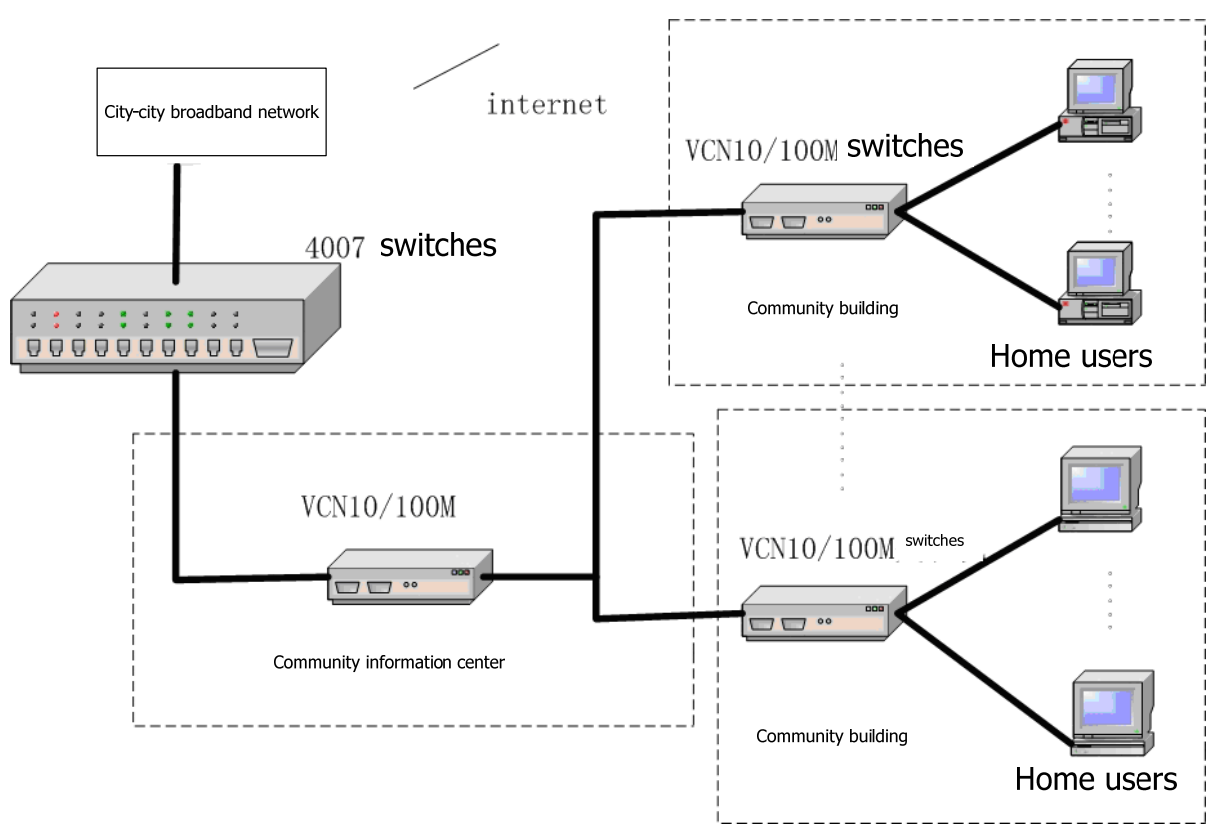

Fig.2.Community Network Access Diagram

Building the intelligent community network system is not only the subject concerning with the enterprise, it is also the important working content of government in accelerating information construction; furthermore, it is necessary to integrate various factors of social development and consider the overall situation with scientific plan, so as to promote development of the intelligent community.

1) The government and enterprises form alliances and build intelligent communities together. The intelligent community is the import working content of the government in promoting the development of social information, which is able to meet residents' living requirements better and improve the people's living standard and quality. Meanwhile, construction of the intelligent community opens a new market for enterprises. If the government can actively promote enterprises to invest and encourage enterprises to actively participate in related projects with policy support for the enterprises, this will relieve the burden of the government in information construction, enlarge the team for community information construction and create more opportunities for the development of the enterprises.2) It is necessary to adjust measures to local conditions with scientific and reasonable development patterns. Because of different specific situations in various countries, the development patterns of these countries are various as well. China is a populous country with the vast territory; there exists a large gap between the economic development levels and corresponding residents' living quality of different regions as well as geographical features; so it is absolutely unsuitable to lump together in building the development pattern of the intelligent community system. It is necessary to establish relevant development patterns according to economic development levels and geographical features of various regions. According to the specific circumstances of different regions, some foreign mature development patterns of the intelligent communities are used as reference, which will yield twice the result with half the effort.

3) The propaganda mode should be perfected and propaganda should be strengthened. At present, community information services have been carried out in many regions of China, such as community networking service, community entertainment system etc., providing a variety of intelligent services (catering, education, maintenance, housekeeping, and so forth) for the public. However, due to lack of the robust propaganda system, the sole propaganda mode and insufficient propaganda make the residents not familiar to these services provided by the community, which makes intelligent devices of many communities useless; therefore these devices cannot play due roles to cause low investment benefit to the involved enterprises. This is certain to produce an effect on initiative and enthusiasm of the enterprises, fail to achieve the purpose of offering benefit to our country and the public through community information construction. Therefore, propaganda of the intelligent community should be 
strengthened and propaganda mode should be completed to make community residents understand and be aware of convenience and benefit from the intelligent services, promoting them to have a try.

4) The intelligent devices are utilized to provide education opportunities. With the development of the computer network technology and popularity of information technology products, the network has become the most convenient media with the most abundant information. If residents are provided with the information required by them by means of community service sites, development of the intelligent community will be rapidly promoted. On the basis of the current situation that some middle and aged residents cannot use the internet, these smart devices of the communities may be employed to provide network education and training for these residents and to offer an learning opportunity to them, which will develop community residents' ability and habit to use the internet and gear up popularity and application of the intelligent community.

\section{Conclusion}

The intelligent building is the product which integrates the modern information technology, the automatic control technology, construction engineering and other science and technology, with the feature of combine of multiple disciplines. Moreover, the environmental planning support system of the intelligent buildings and the construction engineering are the basis of the intelligent buildings, they must meet particular functional requirements of intelligent buildings; intelligentization degree and functions of the intelligent buildings will be further improved and perfected with the increasing development of science and technology, meanwhile the building environment and the construction engineering as the basis of the intelligent buildings will be certain to adapt to this trend. With increasingly close integration and continuous development of computer, communication, automatic control and graphical display technologies, future communication function, information processing and other business types are inevitable to be increased continuously, automatic level and intelligentization level of the intelligent buildings will be certain to be improved as well.

\section{References}

[1]Zhang L,Liu Y. Research on the Evolution Process of Virtual Community Networks[J]. Acta Physica Sinica,2008,57 ( 9) : 5419-5424. ( in Chinese)

[2]Sheffi Y. Urban Transportation Networks: Equilibrium Analysis with Mathematical Programming Methods [M].NJ: Printice-Hall,1985: 231.

[3]Deng L,Liu Y. Research on Opinion Formation and Extremists Modeling in Internet Virtual Community[J]. Journal of Beijing Jiaotong University,2011,35(2) : 66-71. ( in Chinese)

[4] Nagurney A,Dong J.Supernetworks: Decision-Making for the Information Age[M].Cheltenham: Edward Elgar Publishing,2002: 16.

[5]Xu X M,Sun Y G,Yang S,et al. Hypergraph Theory with Applications[J]. Acta Electronica Sinica,1994,22(8) : 65-71.( in Chinese)

[6] Nagurney A. On the Relationship between Supply Chain and Transportation Network Equilibria: a Supernetwork Equivalence with Computations [J]. Transportation Research Part E: Logistics and Transportation Review,2006,42( 4) : 293-316.

[7] Jr Page F H,Wooders M H,Kamat S. Networks and Farsighted Stability[J]. Journal of Economics Theory,2005,120(2) : 257- 269.

[8]Wang Z T,Wang Z P. Elementary Study of Supernetwork[J].Chinese Journal of Management, 2008, 5(1) : 1-8. ( in Chinese) 